\title{
Comparison of Propofol Vs Thiopentone in Post Operative Nausea and Vomiting in Patients Undergoing Laparoscopic Cholecystectomy
}

\author{
Bhuban Raj Kunwar, Thaneshowr Rijal, Puja Thapa, Mallika Rayamajhi and \\ Bishow Ram Amatya
}

Department of Anaesthesiology, Nepalese Army Institute of Health Sciences, Shree Birendra Hospital, Chhauni, Kathmandu, Nepal

\section{ABSTRACT}

Introduction: Postoperative Nausea and Vomiting (PONV) is one of the commonest causes of significant morbidity in the patients after laparoscopic cholecystectomy. The purpose of this study was to compare the incidence of PONV when propofol and thiopentone were used as induction agents during laparoscopic cholecystectomy.

Methods: A prospective, randomised comparative study was conducted in operation theatre at a tertiary level referral hospital of Nepal. A sample size of 100 ASA I - II patients aged between 18 and 70 years were included and scheduled for elective laparoscopic cholecystectomy. The study population were divided into two groups: Group A (Propofol), $n=50$ and Group B (Thiopentone), $n=50$. These patients were followed up for the first 24 hours postoperatively for any PONV at 0-6 hrs, 6-12 hrs, 12-24 hrs.

Results: Out of the 100 patients, PONV was observed almost similar in both groups. i.e. group A (Propofol) $\mathrm{n}=31,(62 \%)$ and group B (Thiopentone) $\mathrm{n}=26(52 \%)$ with no statistical significance (p value $=0.1998)$ within the first 24 hours postoperatively in both groups; and no significant difference was observed at the different time intervals viz. at $0-6$ hrs ( $p$ value 0.262 ): Group A $=45 \%$; Group B = $40 \% ; 6-12$ hrs (p value 0.781 ): Group $A=17.5 \%$, Group $B=22.5 \% ; 12-24$ hrs (p value 1.000 ) Group $A=$ $0 \%$; Group $\mathrm{B}=2.5 \%$ when using the Fisher exact test. The mean ages for development of PONV in these two groups were: Group $\mathrm{A}=40$ years and Group $\mathrm{B}=38$ years. The p-value was 0.5125 which showed no statistical significance. In our study $76 \%(n=38)$ were females and $24 \%(n=12)$ were males in Group A; while $70 \%(n=35)$ were females and $30 \%(n=15)$ males in Group B. However, there was no statistical difference between the two groups in terms of PONV.

Conclusions: The study showed that there was a high incidence of PONV during laparoscopic cholecystectomy. However, there was no significant difference in the incidence of PONV when propofol or thiopentone was used.

Key Words: Laparoscopic cholecystectomy; PONV; Propofol; Thiopentone

Correspondence: Bhuban Raj Kunwar, Department of Anaesthesiology, Nepalese Army Institute of Health Sciences, Shree Birendra Hospital, Chhauni, Kathmandu, Nepal. Email: drbrkunwar@yahoo.com

DOI: $10.3126 /$ mjsbh.v18i1.20506

Submitted on: 2018-07-05

Accepted on: 2018-09-03 


\section{INTRODUCTION}

Post Operative Nausea and Vomiting (PONV) is defined as nausea, retching or vomiting within 24 hours of surgery. ${ }^{1}$ PONV is one of the common problems in the field of anaesthesia and has various risk factors which include age, sex, history of previous PONV or motion sickness, smoking, surgical procedure, and the duration of surgery or anaesthesia. ${ }^{2}$ PONV can result in morbidity like wound dehiscence, bleeding, fluid and electrolyte disturbances, pulmonary aspiration of gastric contents, delayed discharge from the hospital, unexpected hospital admission in day surgeries and patient dissatisfaction. ${ }^{2,3}$

During laparoscopic cholecystectomy, the insufflation of the abdomen with carbon dioxide stimulates the cascade of nausea and vomiting and predisposes to PONV. ${ }^{4}$ There is a strong association between PONV and laparoscopic cholecystectomy.

Thiopentone and propofol which are the anaesthetic induction agents used daily in operation theatres were compared to assess how each of these agents contribute to PONV. However, the actual comparison is not known. The purpose of this study was to compare the incidence of PONV between propofol and thiopentone in patients undergoing laparoscopic cholecystectomy.

\section{METHODS}

A randomised, prospective comparative study was conducted at a tertiary level referral hospital. Randomisation was done by computer generated randomisation table. A sample size of 100 patients was selected, calculated at $95 \%$ confidence interval. Institutional Research Committee approval was obtained and written informed consent was taken from each patient. 100 adult patients of age 18-70 years of ASA-PS I-II undergoing laparoscopic surgery for cholecystectomy were included in the study. Patients with ASA PS III-IV, known allergies to barbiturates or propofol, history of migraine, motion sickness, porphyria, PONV and surgery converted to open cholecystectomy were excluded from the study. In our study, we had used Apfel score 3 and 4 as one of the exclusion criteria. Apfel score includes: (1) female gender, (2) history of PONV and /or motion sickness, (3) non-smoking status, (4) use of opioids in the post operative period. ${ }^{5}$

In the theatre, all the ASA standard monitors were attached to the patient. Patient was pre-medicated with inj. Midazolam $2 \mathrm{mg}$ iv, inj. Fentanyl $1.5 \mathrm{mcg} / \mathrm{kg}$. Induction was done with inj. Propofol $2 \mathrm{mg} / \mathrm{kg}$ or inj. Thiopentone $4 \mathrm{mg} / \mathrm{kg}$ which was determined by randomisation. Muscle relaxation with inj. Vecuronium $0.1 \mathrm{mg} / \mathrm{kg}$ initially and the patient was intubated after pre-oxygenation. Maintenance of anaesthesia by Isoflurane and relaxation with inj. Vecuronium $1 \mathrm{mg}$ was used as required. Reversal was done with inj. Neostigmine $50 \mathrm{mcg} / \mathrm{kg}+$ Glycopyrrolate $10 \mathrm{mcg} / \mathrm{kg}$. Inj. Paracetamol $1 \mathrm{gm}$ i.v. was given as intra-operative analgesia. Inj. Ondansetron $4 \mathrm{mg}$ routinely was given as antiemetics for all patients. For postoperative pain relief, inj. Paracetamol $1 \mathrm{gm}$ iv eight hourly was given and for rescue analgesia for pain score $>4$, inj. Ketorolac $30 \mathrm{mg}$ iv was given. Inj. Metoclopramide $10 \mathrm{mg}$ was given as a rescue treatment for any PONV.

Collected data was analysed by means of statistical software SPSS 20.0. Fisher's Exact test were used to see the association between groups for categorical variables. Two- tailed sample t-test was applied to see significant differences between the groups for continuous variables. The p-value less than 0.05 was taken as significant

\section{RESULTS}

A total of 100 adult patients aged 18-70 years were randomly divided into two groups; group A 
Table 1. Mean age of the patients

\begin{tabular}{|c|c|c|c|c|}
\hline & $\begin{array}{l}\text { Group A } \\
\text { (Propofol) }\end{array}$ & $\begin{array}{c}\text { Group B } \\
\text { (Thiopentone) }\end{array}$ & $\begin{array}{c}p \\
\text { value }\end{array}$ \\
\hline $\begin{array}{l}\text { Mean } \\
\text { age } \\
\text { (yrs) }\end{array}$ & & 44.4 & 46.24 & 0.40 \\
\hline \multirow[t]{2}{*}{ Gender } & M & $76(38)$ & $70(35)$ & 0.71 \\
\hline & $F$ & $24(12)$ & $30(15)$ & 0.26 \\
\hline
\end{tabular}

(Propofol) and group B (Thiopentone). Data was collected for PONV within the first 24 hours after laparoscopic cholecystectomy, the time intervals were: 0-6 hours, 6-12 hours, and 12-24 hours; and no PONV (0-24 hours). P-values were also calculated for the different time intervals. The pvalue $<0.05$ was considered as statistically significant.

The mean ages of the two anaesthetic groups which was 44.4 years for group A and 46.24 years for group B. There was no statistical difference between the two anaesthetic groups, with a p-value is 0.406 (Table 1). There were more females than males in both groups: $76 \%(\mathrm{n}=38)$ females and $24 \%(n=12)$ males in group $A ; 70 \%(n=35)$ females and $30 \%(n=15)$ males in group $B$. There was no statistical difference in terms of PONV between the two anaesthetic groups when females and males were compared. The $\mathrm{p}$ value is 0.7105 for females and 0.2666 for males.
Table 2. Incidence of PONV at different time

\begin{tabular}{|l|l|l|l|}
\hline & \multicolumn{1}{|c|}{$\begin{array}{c}\text { Group A } \\
\text { (Propofol) }\end{array}$} & $\begin{array}{c}\text { Group B } \\
\text { (Thiopentone) }\end{array}$ & $\begin{array}{c}\text { p } \\
\text { value }\end{array}$ \\
\hline $\begin{array}{l}\text { PONV } \\
\text { (0-6 hrs) }\end{array}$ & $22(44 \%)$ & $20(40 \%)$ & 0.262 \\
\hline $\begin{array}{l}\text { PONV } \\
(\mathbf{6}-12 \text { hrs) }\end{array}$ & $9(18 \%)$ & $11(22 \%)$ & 0.781 \\
\hline $\begin{array}{l}\text { PONV } \\
(\mathbf{1 2 - 2 4} \text { hrs) }\end{array}$ & $0(0 \%)$ & $2(4 \%)$ & 1.000 \\
\hline $\begin{array}{l}\text { Total } \\
\text { PONV }\end{array}$ & $31(62 \%)$ & $33(66 \%)$ & 0.939 \\
\hline No PONV & $19(38 \%)$ & $17(34 \%)$ & 0.175 \\
\hline
\end{tabular}

The incidence was highest during the first interval and decreased as time progressed. The incidence in the first interval 0-6 hours ( $\mathrm{A}=44 \%$ and $\mathrm{B}=40 \%$ ); in second interval 6-12 hours $(\mathrm{A}=18 \%$ and $\mathrm{B}=22 \%)$; and was lowest during the third interval 12-24 hours $(\mathrm{A}=0 \%$ and $\mathrm{B}=2 \%)$. There was not much difference in terms of PONV between the two anaesthetic drugs. The p-values shown are: 0.262 at 0-6 hours, 0.781 at 6-12 hours and 1.000 at $12-24$ hours. The overall incidence of PONV was $62 \%$ (31) for the propofol group and 66\% (33) for the thiopentone group with p-value of 0.178 (Table 2).

At $0-6$ hours 22 of the $22(100 \%)$ patients who experienced PONV in the propofol group received rescue treatment and 20 of $20(100 \%)$ patients in the thiopentone group received rescue treatment. At 6 to 12 hours, 4 of $9(44.4 \%)$ of patients in the propofol group received rescue treatment; and 6 of

Table 3. Rescue treatment for PONV

\begin{tabular}{|c|c|c|c|c|c|c|}
\hline & \multicolumn{2}{|r|}{$0-6$ hrs } & \multicolumn{2}{|r|}{$6-12 \mathrm{hrs}$} & \multicolumn{2}{|r|}{$12-24 \mathrm{hrs}$} \\
\hline & PONV & Rescue treatment & PONV & Rescue treatment & PONV & Rescue treatment \\
\hline $\begin{array}{l}\text { Propofol } \\
(\mathbf{n}=\mathbf{5 0})\end{array}$ & 22 & $\begin{array}{r}22 \\
(100 \%)\end{array}$ & 9 & $\begin{array}{r}4 \\
(44.4 \%)\end{array}$ & 0 & 0 \\
\hline $\begin{array}{l}\text { Thiopentone } \\
(\mathbf{n}=\mathbf{5 0})\end{array}$ & 20 & $\begin{array}{r}20 \\
(100 \%)\end{array}$ & 11 & $\begin{array}{r}6 \\
(54.6 \%)\end{array}$ & 2 & $\begin{array}{r}2 \\
(100)\end{array}$ \\
\hline p-value & & & & 0.1631 & & \\
\hline
\end{tabular}


Table 4. Mean duration of operation

\begin{tabular}{|l|r|r|r|r|r|}
$\begin{array}{l}\text { Anaesthetic } \\
\text { group }\end{array}$ & N & Mean & SD & \multicolumn{2}{c}{$\begin{array}{c}95 \% \\
\text { CI } \\
\text { Min }\end{array}$} \\
\hline A & 50 & 67.2 & 1.2187 & 45 & 95 \\
\hline B & 50 & 66.6 & 1.0223 & 45 & 100 \\
\hline
\end{tabular}

$11(54.6 \%)$ patients in the thiopentone group received rescue treatment, with a $p$-value of 0.1631 when Fischer exact test was used. There was a dramatic decline over time in the percentage of patients who received rescue treatment from 0-6 hours to 6-12 hours for both groups (Propofol and Thiopentone), from $100 \%$ to $44.4 \%$ for propofol and from $100 \%$ to $54.6 \%$ for thiopentone (Table 3). The mean duration of operation was 67.2 mins for group A and 66.6 mins for group B and there was no statistical difference between the two groups, with p-value 0.953 (Table 4).

\section{DISCUSSION}

PONV is one of the most commonly reported adverse effects of anaesthesia. The incidence of PONV varies according to patient's risk factors. Even patients with no known risk factors carry a $10 \%$ risk of $\mathrm{PONV}$, and this risk increases dramatically to $61 \%$ and $79 \%$, respectively when three or four risk factors exist (female gender, nonsmoker, history of motion sickness or PONV, and postoperative opioid use). ${ }^{6}$

The complex act of vomiting involves coordination of the respiratory, gastrointestinal and abdominal musculature. The main coordinator is the vomiting centre which is a collection of neurones located in the medulla oblongata. ${ }^{2,7}$ The vomiting centre receives inputs from Chemoreceptor Trigger Zone (CTZ) in the area postrema, vestibular system, higher cortical centres (e.g. limbic system), mechanoceptors on muscular wall of gut via afferent vagus nerve, chemoceptors in the upper GI mucosa, spinoreticular system, nucleus tractus solitarius. There are various surgical risk factors for PONV including the laparoscopic surgery, ENT surgeries, strabismus surgery and long duration surgery ( $>2$ hours). 5,8 Similarly anaesthetic risk factors like inhalational anaesthesia, use of opioids, neostigmine increases the incidence of PONV.9,10 The patient factors for increased PONV include female gender (2-4 times increased incidence), younger age group, obesity, non-smokers, history of motion sickness or previous history of PONV. ${ }^{11,12}$ Similarly, post operative factors like hypotension pain, early ambulation. ${ }^{8}$

In our study, the overall incidence was $62 \%$ (31 of 50 ) for the Propofol group A and 66\% (33 of 50) for Thiopentone group $\mathrm{B}$ and there was no significant difference in terms of PONV when these two induction agents were used with p-value 0.178. Contrary to our study results, Chanvej et al. ${ }^{13}$ in their study of 180 patients undergoing laparoscopic surgery compared the incidence of PONV when thiopentone with halothane $(\mathrm{T} / \mathrm{H})$ and propofol with halothane $(\mathrm{P} / \mathrm{H})$ as anaesthetics and found that incidence of nausea in $\mathrm{T} / \mathrm{H}$ was $72 \%$ and $\mathrm{P} / \mathrm{H}$ was $44 \%$ ( $\mathrm{p}=0.002, \quad$ statistically significant $)$ while incidence of vomiting in $\mathrm{T} / \mathrm{H}$ was $58 \%$ and $\mathrm{P} / \mathrm{H}$ was $36 \%$, ( $p=0.00014$, statistically significant). The results of our study is similar to that done by Miles et al., ${ }^{14}$ which showed the incidence of PONV in propofol to be $63 \%$ and thiopentone $53 \%$ respectively in adults undergoing elective surgery. It could not detect any differences $(p$-value $=0.13$ ) of propofol in preventing PONV. This potential benefit may have been obscured by coadministration of opioids (e.g. fentanyl), or other drugs like neostigmine and volatile agents (e.g. isoflurane). Similarly, Klockgether et al. 15 in their study found that that there is no difference of PONV when these induction agents were used, the incidence of PONV to be $43 \%$ in the thiopentone 
group and $23 \%$ in the propofol group, $\mathrm{p}=0.17$ (not statistically significant).

The incidence of PONV was highest in the early postoperative period ( $0-6$ hours) for both groups: $44 \%$ for group A and $40 \%$ for group B. The incidence decreased as time progressed: $18 \%$ for group A and 22\% for group B at 6-12 hours; and within the last 12-24 hours the incidence was almost negligible $0 \%$ for group $\mathrm{A}$ and $4 \%$ for group B. The p-values were: 0.262 at $0-6$ hours; 0.781 at 6-12 hours and 1.000 at 12-24 hours, all of which were not statistically significant.

In our study, patients who experienced PONV were given rescue treatment (Inj. Metoclopramide 10 $\mathrm{mg}$ ). The number of patients who were given rescue treatment was high. It was highest during the first 0-6 hours for both anaesthetic groups: 22 of 22 $(100 \%)$ for propofol and 20 of $20(100 \%)$ for thiopentone. This number declined at 6-12 hours to 4 of 9 (44.4\%) for the propofol group and 6 of 11 (54.6\%) for the thiopentone group but there was no statistical difference between the two groups with a p-value of 0.1631 . At $12-24$ hours there was no patient who vomited hence none required rescue treatment for the propofol group and two patients vomited for the thiopentone group hence two required rescue treatment. Joshi et al. in their study, despite giving the prophylactic antiemetic (Ondansetron $4 \mathrm{mg}$ ) for PONV in 50 patients undergoing laparoscopic surgery, showed the higher incidence of PONV at: 0-6 hours $=24$ $(48 \%), 6-12$ hours $=10(20 \%)$ and $12-24$ hours $=$ $10(20 \%)$, requiring rescue treatment metoclopramide $10 \mathrm{mg} .{ }^{16}$

In this study, the mean duration of surgery was 67.2 minutes for propofol group and 66.6 minutes for thiopentone group, hence posing lesser contribution to the incidence of PONV. There was no significant difference in terms of PONV when the two anaesthetic agents were used ( $\mathrm{p}$-value $=0.1998)$.
According to Pierre, longer duration of the procedure positively correlated with a greater likelihood of the development of PONV. ${ }^{9}$ Increasing the duration by 30 minutes may increase the risk of PONV by $60 \%$.

Sinclair et al., found that the incidence of PONV increased from $2.8 \%$ among patients with surgical duration less than 30 minutes to $27.7 \%$ among patients with surgery lasting 151 to 180 minutes. However, contrary to this study, the incidence of PONV with a duration less than 90 minutes was higher at $17.5 \%$ compared to $12.5 \%$ in procedures lasting 90 to 150 minutes in a study by Aftab S et al. ${ }^{17}$

According to Miller, although the incidence of PONV decreases with age in adults, it has not always been a strong risk factor. ${ }^{18}$ The patients included in our study were adults with a mean age of 40-50 years and there was no statistical difference ( $p$-value $=0.5925$ ) between the two anaesthetic groups in terms of PONV when the two-tailed sample t-test was used.

The majority of patients in this study were female, which is another risk factor for PONV. Females were $38(76 \%)$ while males were only $12(24 \%)$ in group A; and females were $35(70 \%)$ as opposed to $15(30 \%)$ males in group B. However, there was no statistical difference of PONV between the two anaesthetic groups with a for females and 0.2666 for males when the Fisher exact test was used. Even though this study did not confirm the fact that females are more susceptible to PONV than males, a study by Aftab et al. ${ }^{18}$, stated that females experienced a higher incidence of PONV (20\%) compared to males $(10 \%)$.

Pain, which is another risk factor for PONV was controlled in this study by using non-opioid analgesia which included paracetamol, ketorolac and local anaesthetic (bupivacaine $0.5 \%$ ) on 
surgical site. Therefore, avoiding opioids post operatively reduces the incidence of PONV but this fact was not evident in this study as other risk factors contributed to increasing the incidence of PONV. Pain triggers PONV by increasing catecholamines that directly affect the CTZ hence causing nausea and vomiting.

\section{CONCLUSIONS}

The overall incidence of PONV in patients undergoing laparoscopic cholecystectomy is high but no significant difference in PONV was observed between propofol and thiopentone when used as inducing agents.

To cite this article: Kunwar BR, Rijal T, Thapa P, Rayamajhi M, Amatya BR. Comparison of Propofol Vs Thiopentone in post operative nausea and vomiting in patients undergoing laparoscopic cholecystectomy. MJSBH. 2019;18(1):23-9.

Conflict of Interest: None declared

\section{REFERENCES}

1. Rother C. Postoperative nausea and vomiting - Use of anti-emetics in anaesthesia. SUMJ. 2012 Feb; 1(1):89-97.

2. Rahman MH, Beattie J. Postoperative nausea and vomiting. Pharmaceutical Journal. 2004 Nov; 273:786-8.

3. Rose JB, Watch MF. Post-op nausea and vomiting in paediatric patients. BJA. 1999;83:104-17.

DOI: https://doi.org/10.1093/bja/83.1.104

4. Thompson GE, Vanagunas AD. Laparoscopic Gallbladder Surgery of gallstones. Healthwise. 2011 July.

5. Apfel CC, Kranke P, Katz MH. Volatile anaesthesia may be the main cause of early but not delayed postoperative nausea and vomiting: a randomized controlled trial of factoria design. BJA. 2002;88: $659-68$.

DOI: https://doi.org/10.1093/bja/88.5.659

6. Smith HS, Smith EJ, Smith BR. Postoperative nausea and vomiting. 2012;1(2).

7. Coleen J Gibbon. South African Formulary. 9th Edition. 2010:43-53.

8. Alkaissai A, Kalman S. Postoperative Symptoms After Gynaecological Surgery. Linkoping University Medical Dissertation No. 851. 2004.

9. Amponsah Gladys. PONV in Korle Bu Teaching Hospital. Ghana Med J. 2007 Dec;41(4): 181-5. PMID: 18464904

10. Joshi GP, Garg SA, Hailey A, Song Y. The effects of antagonising residual neuromuscular blockade by neostigmine and glycopyrrolate on nausea and vomiting after ambulatory surgery. Anaesth Analg. 1999 Sep;89(3): 628-31.

DOI: 10.1213/00000539-199909000-00015

PMID: 10475292

11. Cheng CR, Sessler D, Apfel CC. Does neostigmine administration produce a clinically important increase in PONV. Anaesth Analg. 2005 Nov;101(5):1349-55.

DOI: https://doi.org/10.1213/01.ANE.0000180992.76743.C9

12. Tinsely MH, Barone CP. Preventing PONV. Nursing 2018. 2013 Dec;43(12):42-9. 
13. Chanvej L, Kijsirikul S, Thongsuksai P. PONV in outpatient gynaecologic laparascopy: a comparison of thiopentone-nitrous oxide, propofol-nitrous oxide and total intravenous anaesthesia using propofol. $\mathrm{J}$ Medical Assoc Thai. 2001 May;84(5):697-704.

PMID: 11560221

14. Myles PS, Hunt JO, Fletcher H, Smart J, Jackson T. Part I: propofol, thiopental, sevoflurane, and isoflurane - a randomised, controlled trial of effectiveness. Anesth Analg. 2000 Nov;91(5):1163-9.

DOI: https://doi.org/10.1213/00000539-200011000-00023

15. Klockgether RA, Piorek V, Crozier T, Kettler D. Nausea and vomiting after laparascopic surgery, a comparison of propofol and thiopentone/ halothane anaesthesia. EJA. 1996 Jan;13(1):3-9.

DOI: https://doi.org/10.1097/00003643-199601000-00002

16. Joshi H, Parmar P, Raval B. Comparison of Ondansetron/Palonosetron for prevention of PONV in laparoscopic surgery. RJPBCS. 2014;5(4): 54-63.

17. Sabqa A, Abdul BK, Raza Ghulam. The assessment of Risk Factors for PONV. JCPSP. 2008;18(3): $137-41$.

18. Miller Ronald D. Miller's Anesthesia. 8th Edition, 2014. 